\title{
Assessment of Soil on Some Heavy Metals and its Pollution in Roodsar-Iran
}

\author{
Ebrahim Alinia-Ahandani ${ }^{1 *}$, Zahra Alizadeh-Terepoei ${ }^{2}$, Milad Sheydaei ${ }^{3}$, Fatemeh Peysepar- \\ Balalami $^{1}$ \\ ${ }^{1}$ Department of Biochemistry, Payame Noor University, P.O. Box 19395-3697, Tehran, Iran \\ ${ }^{2}$ Department of Biology, Faculty of Basic Sciences, University of Gilan, Rasht, Iran
}

${ }^{3}$ Faculty of Polymer Engineering, Sahand University of Technology, P.O. Box 51335-1996, Tabriz, Iran

*Corresponding author: Ebrahim Alinia-Ahandani, Department of Biochemistry, Payame Noor University, Tehran, I.R. Iran

ARTICLE INFO

Received: 慧 July 03, 2020

Published: July 14, 2020

Citation: E Alinia-Ahandani, Z Alizadeh-Terepoei, F Peysepar-Balalami. Assessment of Soil on Some Heavy Metals and its Pollution in Roodsar-Iran. Biomed J Sci \& Tech Res 28(5)-2020. BJSTR. MS.ID.004714.

\author{
ABSTRACT
}

Increased concentrations of heavy metals in the air, soil, or water threatens human health both directly and indirectly via accumulation in the food chain. In countries with high ecological awareness the risk of acute exposure has been minimized thanks to the enforcement of restoration laws and policies. This paper presents results of chemical analysis of soil samples to total content of $\mathrm{Pb}, \mathrm{Ni}, \mathrm{Cr}$ and $\mathrm{Cu}$. Samples were collected at site of Roodsar, at two depths in November 2019th year. These heavy metals were analyzed using three methods of sample preparation. Method of sample preparation, which defines the standard ISO 11047:2000 proved to be best. Results show that content of these heavy metals exceeding limit values. Analyses were done on device, Atomic Absorption.

Keywords: Soil; Heavy Metals; Sample; Atomic; Contamination

\section{Introduction}

Over the past several decades, industrial activity in the mining and smelting sectors has caused serious environmental pollution by heavy metals on a global scale. Increased concentrations of heavy metals in the air, soil, or water threatens human health both directly and indirectly via accumulation in the food chain. In countries with high ecological awareness the risk of acute exposure has been minimized thanks to the enforcement of restoration laws and policies. The risk of chronic effects, however, is still there [1-13]. Heavy metals are chemical elements whose relative density is greater than $5 \mathrm{gdm}^{-3}$. Heavy metals are classified as essential microelements which include $\mathrm{Cu}, \mathrm{Fe}, \mathrm{Mn}, \mathrm{Zn}, \mathrm{Mo}, \mathrm{Ni}$ and potentially toxic or nonessential elements as $\mathrm{Cd}, \mathrm{Cr}, \mathrm{Pb}, \mathrm{Hg}$ and $\mathrm{As}$. In soil coming through rain, dust and soot. Plants can also be deposited heavy metals from deeper soil layers in upper layer. Also, fertilization of soil comes a certain amount of heavy metals. However, major anthropogenic sources of soil pollution with heavy metals are intense traffic, metal industry, mining, organic and mineral fertilizers and municipal waste. Environment region of Guilan in Iran is several decades exposed to emissions of heavy metals and other pollutants emitted from metallurgical and thermal power plants [5-7]. It is known that atmospheric deposition of heavy metals due to soil in which maximum reserve in relation to other components of environment. Usually linger for years in upper layer and very difficult to amounts of soil [1,8-11]. Heavy metals can accumulate in large quantities in soil and can cause multiple ecological consequences of which are considered major polluters of environment $[5,12,13]$.

\section{Experimental Sections}

a. Conducted an experiment had two objectives which are: To analyze heavy metals in soil samples using different digestion methods to determine most effective methods,

b. To assess soil contamination by comparing results of limit values of heavy metals as defined in the Regulations that are defined $[14,15]$.

Samples were collected in some various parts because it 
is a location near industrial plants. Samples of soil mass by approximately $1.0 \mathrm{~kg}$ were prepared for analysis in laboratory of Faculty of Biology in Payame Noor university of Roodsar. Primary soil samples were taken with an area of $9 \mathrm{~m}^{2}$, so that surface is divided into nine equal plots and each of them has taken about $110 \mathrm{~g}$ soil [16-18]. Reducing size of primary sample of size suitable for laboratory work was carried out after primary sample dried $24 \mathrm{~h}$ at $105^{\circ} \mathrm{C}$, chopped and sieved. Samples were prepared in two ways: wet and dry digestion $[5,17,19,20]$. In wet digestion are used two types of reagents, table 1 . Samples were prepared with super pure acids. In both cases, $1 \mathrm{~g}$ sample was added $10 \mathrm{ml}$ of reagent. When digestion is carried sediment diluted with distilled water to $50 \mathrm{ml}$. For dry digestion was $1.5 \mathrm{~g}$ sample is gradually heated to $450^{\circ} \mathrm{C}$. Ash was obtained by annealing was dissolved in $5 \mathrm{ml}$ of concentrated $\mathrm{HCl}$ and solution was evaporated to dryness. Sediment is then dissolved in $0.1 \mathrm{M} \mathrm{HNO}_{3}$ to $50 \mathrm{ml}$. Analysis of samples was performed by flame technique on device, "Atomic absorption spectrophotometer, Perkin Elmer, A Analyst 800".

\section{Results and Discussion}

Results of analysis of investigated heavy metals in soil defined

Table 1: Concentrations of heavy metals in soil. location are given in Table 1. From results, Table 1, it is evident that as best method of sample preparation using wet digestion with $\mathrm{HCl}: \mathrm{HNO}_{3}=3: 1$. Above method is a standard method for preparation and analysis of soil samples, standard ISO 11047:2000. Examining influence of soil depth on content of heavy metals, Table 1, it is evident that content of all investigated heavy metals slightly decreases with increasing depth, which is to be expected $[21,22]$. Results of many studies show that highest concentrations of heavy metals detected exactly at depth $0-5 \mathrm{~cm}$, because greatest amount of heavy metals after arrival and migration in soil to retain a depth of $5 \mathrm{~cm}[3,5,6,13]$. Metal transport is not only dependent on physiochemical properties of metals but mostly on physical and chemical properties of soil, like for example: soil organic matter content, clay fraction content, mineralogical composition, $\mathrm{pH}$, and more, all of which collectively determine binding ability of soil $[8,12,17,19]$. Based on results in Table 1 can be concluded that contents of $\mathrm{Pb}, \mathrm{Ni}, \mathrm{Cr}$ and $\mathrm{Cu}$ in almost all samples, prepared using three techniques of preparation, in both investigated depths, significantly higher than limit value. It is therefore necessary to take measures to reduce emissions of heavy metals from primary metallurgical plants and soil remediation measures for protection of human health $[4,7,12,17]$.

\begin{tabular}{|c|c|c|c|c|c|}
\hline \multirow{5}{*}{ Heavy metals } & \multirow{5}{*}{$\begin{array}{l}\text { Depth of soil } \\
\text { sampling }\end{array}$} & \multicolumn{3}{|c|}{ Digestion technique } & \multirow{5}{*}{ Limits values, mgkg ${ }^{-1}$} \\
\hline & & & & Dry digestion & \\
\hline & & \multicolumn{2}{|c|}{ Reagents for digestion } & $\begin{array}{l}\text { Reagents for } \\
\text { digestion }\end{array}$ & \\
\hline & & $\mathrm{HCl}: \mathrm{HNO}_{3} 3: 1$ & $\mathrm{HNO}_{3}$ & $\mathrm{HCl}+0,1 \mathrm{M} \mathrm{HNO}_{3}$ & \\
\hline & & \multicolumn{3}{|c|}{ Concentration of heavy metal, mgkg $^{-1}$} & \\
\hline \multirow{2}{*}{$\mathrm{Pb}$} & Depth of $5 \mathrm{~cm}$ & 153,85 & 153,15 & 141,13 & \multirow{2}{*}{100} \\
\hline & Depth of $15 \mathrm{~cm}$ & 146,6 & 144,7 & 136,63 & \\
\hline \multirow{2}{*}{$\mathrm{Ni}$} & Depth of $5 \mathrm{~cm}$ & 111,45 & 119,5 & 103,03 & \multirow{2}{*}{50} \\
\hline & Depth of $15 \mathrm{~cm}$ & 119,7 & 80,55 & 100,09 & \\
\hline \multirow{2}{*}{$\mathrm{Cr}$} & Depth of $5 \mathrm{~cm}$ & 103,4 & 104,9 & 70,4 & \multirow{2}{*}{100} \\
\hline & Depth of $15 \mathrm{~cm}$ & 99 & 100,2 & 67,77 & \\
\hline \multirow{2}{*}{$\mathrm{Cu}$} & Depth of $5 \mathrm{~cm}$ & 104,05 & 90,05 & 129,15 & \multirow{2}{*}{80} \\
\hline & Depth of $15 \mathrm{~cm}$ & 101,85 & 83,85 & 111,87 & \\
\hline
\end{tabular}

\section{Conclusion}

For analysis of heavy metals in soil, as a method of sample preparation is best to use a wet digestion with $\mathrm{HCl}: \mathrm{HNO}_{3}=3: 1$. Examining influence of soil depth on content of heavy metals it is evident that content of all investigated heavy metals slightly decreases with increasing depth, which is to be expected. Contents of $\mathrm{Pb}, \mathrm{Ni}, \mathrm{Cr}$ and $\mathrm{Cu}$ in almost all tested samples of soil at the region of Roodsar was significantly higher than limit value [23-27].

\section{References}

1. Mohammadi C, E Alinia-Ahandani (2020) Plant-based diets and cardiovascular disease. Open J. Cardiol. Heart Dis 3(2).
2. Alinia-Ahandani E, Boghozian A, Alizadeh Z (2019) New Approaches of Some Herbs Used for Reproductive Issues in the World: Short Review. J Gynecol Women's Health 16(1): 555927.

3. Sheydaei M, E Alinia-Ahandani (2020) Synthesis and characterization of methylene-xylene-based polysulfide block-copolymer/carbon nanotube nanocomposites via in situ polymerization method J. Sulfur Chem 41(4): 421-434.

4. Alinia-Ahandani E, Sheydaei M (2020) Overview of the Introduction to the New Coronavirus (Covid19): A Review. Journal of Medical and Biological Science 6(2): 14-20.

5. OE Orisakwe, JK Nduka, CN Amadi, D Dike, OO Obialor (2012) Evaluation of potential dietary toxicity of heavy metals of vegetables," Journal of Environmental \& Analytical Toxicology 2(3): 136-139.

6. Alinia-Ahandani E, M Fazilati Z Alizadeh, A Boghozian (2018) The introduction of some mushrooms as an effective source of medicines in 
Iran Northern. Biol. Med 10:5.

7. Ahandani,I., Asadisamani,M, Biranvand M (2010) The introduction of nettle. Monthly of Barzegar 1042:43.

8. Rieuwerts JS, Thornton I, Farago ME, Ashmore MR (1998) Factors influencing metal bioavailability in soils: preliminary investigations for the development of a critical loads approach for metals. Chem Spec Bioavailab 10(2): 61-75.

9. Alinia-Ahandani E (2019) Opened approaches on treatment and Herbs' location in Iran. Am. J. Biomed. Sci. Res 5(5): 394-397.

10. Alinia-Ahandani E (2018) Medicinal plants with disinfectant effects. J. Pharm. Sci. Res 10: 1-1.

11. SM Li, Y Fang, HM Ning, YX Wu (2012) Heavy metals in Chinese therapeutic foods and herbs, Journal of the Chemical Society of Pakistan 34(5): 1091-1095

12. Alinia-Ahandani E (2019) Positive Role of Green Tea as An Anti-Cancer Biomedical Source in Iran Northern. Am J Biomed Sci \& Res 5(1).

13. GJ Fosmire (1990) Zinc toxicity, American Journal of Clinical Nutrition 51(2): 225-227.

14. Alinia-Ahandani E, Kafshdar-Jalali H, Mohammadi Ch (2019) Opened Approaches on Treatment and Herbs' Location in Iran. Am J Biomed Sci \& Res 5(5).

15. R Ulla, JA Khader, I Hussain, NM AbdElsalam, M Talha, N Khan (2012) Investigation of macro and micro-nutrients in selected medicinal plants, African Journal of Pharmacy and Pharmacology 6(25): 1829-1832.

16. Alinia-Ahandani E (2018) Medicinal plants and their usages in cancer. J. Pharm. Sci. Res 10: 2-2.

17. Alinia-Ahandani E (2018) Medicinal plants effective on pregnancy, infections during pregnancy, and fetal infections. J. Pharm. Sci. Res 10 3-3.

ISSN: 2574-1241

DOI: 10.26717/BJSTR.2020.28.004714

Ebrahim Alinia-Ahandani. Biomed J Sci \& Tech Res

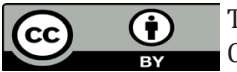

This work is licensed under Creative

Commons Attribution 4.0 License

Submission Link: https://biomedres.us/submit-manuscript.php
18. Ahandani EA, R Taasobi (2015) Some media effects on children-a review. Int. J. Innov. Res. Educ. Sci 2: 48-53.

19. Alinia-Ahandani E, Alizadeh-Terepoei Z, Sheydaei M (2020) Some Pointed Medicinal Plants to Treat the Tick-Borne Disease. Op Acc J Bio Sci \& Res 1(5).

20. Alinia-Ahandani E (2018) Milk-increasing medicinal plants. J Pharm Sci Res 10: 4-4

21. Ahandani EA, MRA Gawwad, A Yavari (2013) Extraction and preparation of psoralen from different plant part of psoraleacorylifolia and psoralen increasing with some elicitors. J. Plant Biol. Res 2: 25-37.

22. E Ernst (2002) Toxic heavy metals and undeclared drugs in Asian herbal medicines, Trends in Pharmacological Sciences 23(3): 136-139.

23. Alinia-Ahandani E, M Fazilati, A Boghozian, M Alinia-Ahandani (2019) Effect of ultraviolet (UV) radiation bonds on growth and chlorophyl content of Dracocephalum moldavica L herb. J. Biomol. Res. Ther 8(1).

24. Gasser U, Klier B, Kühn AV, Steinhoff B (2009) Current findings on the heavy metal content in herbal drugs. Pharmeur Sci Notes 1: 37-50.

25. R Chizzola, H Michitsch, C Franz (2003) Monitoring of metallic micronutrients and heavy metals in herbs, spices and medicinal plants from Austria, European Food Research and Technology 216(5): 407-411.

26. Alinia-Ahandani, E, Sheydaei M, Shirani-Bidabadi B, Alizadeh-Terepoei Z (2020) SOME EFFECTIVE MEDICINAL PLANTS ON CARDIOVASCULAR DISEASES IN IRAN- A REVIEW. J. Global Trends Pharm Sci 11(3): 80218033.

27. Alinia-Ahandani E, Nazem H, Boghozian A, Alizadeh Z (2019) Hepatitis and some effective herbs: A review. EAS J. Parasitol. Infect. Dis 1(1): 20-27.

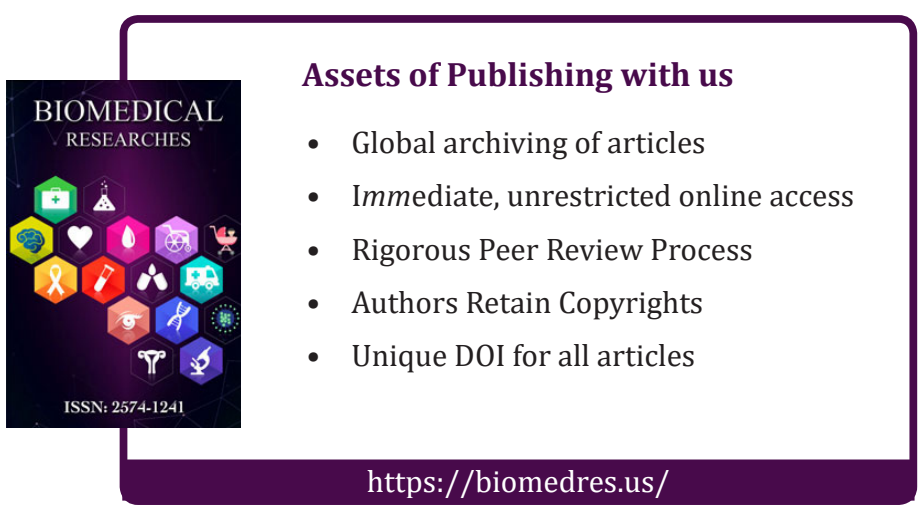

